\title{
VEGFR-1 blockade disrupts peri-implantation decidual angiogenesis and macrophage recruitment
}

\author{
Vascular Cell 6:16 I DOI: 10.1186/2045-824X-6-16 I C Li et al.; licensee Publiverse Online S.R.L. 2014 \\ Received: 31 Mar 2014 | Accepted: 21 Mar 2014 | Published: 1 Mar 2014 \\ Douglas Nataki C ${ }^{@}$, Zimmermann Ralf C, Tan Qian Kun, Sullivan-Pyke Chantae S, Sauer Mark V, \\ Kitajewski Jan K, Shawber Carrie J \\ ${ }^{+}$Contributed equally ${ }^{@}$ Corresponding author
}

\begin{abstract}
Background

Angiogenesis and macrophage recruitment to the uterus are key features of uterine decidualization; the progesterone-mediated uterine changes that allow for embryo implantation and initiation of pregnancy. In the current study, we characterized the expression of vascular endothelial growth factor receptor-1 (VEGFR-1) in macrophages and endothelial cells of the peri-implantation uterus and determined if VEGFR-1 function is required for decidual angiogenesis, macrophage recruitment, and/or the establishment of pregnancy.
\end{abstract}

\section{Methods}

Expression of VEGFR-1 in uterine endothelial cells and macrophages was determined with immunohistochemistry. To assess the effect of continuous VEGFR-1 blockade, adult female mice were given VEGFR-1 blocking antibody, MF-1, every 3 days for 18 days. After 6 doses, females were mated and a final dose of MF-1 was given on embryonic day 3.5. Endothelial cells and macrophages were quantified on embryonic day 7.5. Pregnancy was analyzed on embryonic days 7.5 and 10.5 .

\section{Results}

$\mathrm{F} 4 / 80^{+}$macrophages are observed throughout the stroma and are abundant adjacent to the endometrial lumen and glands prior to embryo implantation and scatter throughout the decidua post implantation. VEGFR-1 expression is restricted to the uterine endothelial cells. $\mathrm{F} 4 / 80^{+}$macrophages were often found adjacent to VEGFR $-1^{+}$endothelial cells in the primary decidual zone. Continuous VEGFR-1 blockade correlates with a significant reduction in decidual vascular and macrophage density, but does not affect embryo implantation or maintenance of pregnancy up to embryonic day 10.5 .

\section{Conclusions}

We found that VEGFR-1 functions in both decidual angiogenesis and macrophage recruitment to the implantation site during pregnancy. VEGFR-1 is expressed by endothelial cells, however blocking VEGFR-1 function in endothelial cells results in reduced macrophage recruitment to the uterus. VEGFR-1 blockade did not compromise the establishment and/or maintenance of pregnancy.

\section{Keywords}

VEGFR-1 - Decidua - Uterus - Implantation - Endothelial cells - Macrophages - Angiogenesis

\section{Introduction}


Implantation of the fertilized oocyte induces uterine decidualization, the rapid proliferation and differentiation of stromal fibroblasts into glycogen and lipid rich decidual cells. Endothelial cells within the decidua proliferate to form a rudimentary vascular plexus necessary to maintain pregnancy prior to placenta development [ $1-3]$. Cells of the innate immune system, including natural killer cells and macrophages, infiltrate the decidua and function to establish and maintain maternal-fetal tolerance [ 4, 5]. These events are coordinated by ovarian estrogen and progesterone. Angiogenesis during decidualization is required for a successful pregnancy, however the signaling pathways that regulate this process have yet to be fully characterized.

In mice and non-human primates, VEGF mediates the increased uterine vascular permeability and decidual angiogenesis required for embryo implantation [ 6- 8]. We have shown that the VEGF receptors (VEGFR-1, VEGFR-2, and VEGFR-3) are expressed in distinct patterns in the peri-implantation uterine decidua [ 9]. To investigate the requirement for VEGF receptor signaling in the decidua, we administered a single, periimplantation (E3.75) dose of blocking antibody against VEGFR-1, VEGFR-2, or VEGFR-3, in a progesteronereplaced, ovariectomized mouse model. Inhibition of VEGF-A receptor, VEGFR-2, blocked decidual angiogenesis observed at E7.5 and resulted in an aborted pregnancy prior to E10.5, while VEGFR-3 inhibition moderately reduced decidual angiogenesis but had no effect on pregnancy [ 9]. In contrast, VEGFR-1 blockade at a single E3.75 time-point did not effect decidual angiogenesis or disrupt pregnancy [ 9].

Embryo implantation and trophoblast invasion create a pro-inflammatory environment leading to the recruitment of immune cells that mediate maternal tolerance to the semi-allogeneic embryo [ 5, 10]. Decidual macrophages are the second most abundant immune cell population at the implantation site, comprising 20-30\% of immune cells in the uterine decidua [ 4,11,12]. Dysregulated macrophage activation in the decidua has been implicated in recurrent miscarriages [13]. Decidual macrophage numbers, as well as the proportion of proapoptotic Fas ligand expressing decidual macrophages, are increased in spontaneous miscarriages [14]. Thus, understanding the signaling pathways that regulate decidual macrophages may elucidate causes of early pregnancy failures.

Macrophages are closely associated with endothelial cells during physiologic angiogenesis during ovarian corpus luteum development and postnatal retinal development, [ 15, 16]. Activation of macrophage VEGFR-1 has a role in macrophage recruitment to sites of active angiogenesis [ 17, 18]. Macrophages have been implicated in promoting angiogenesis by releasing pro-angiogenic factors such as VEGF-A and angiopoietin [ 15] and in anastomosis, the formation of a bridge between two angiogenic tip cells followed by vascular sprout fusion [ 15, 19]. Ablation of ovarian macrophages leads to significant endothelial cell depletion and hemorrhage $[16,20]$. Macrophages have been implicated in the pregnant uterus, including acting in the coordination of the maternal immune response and promoting angiogenesis. However, the relationship between decidual macrophages, endothelial cells and VEGFR-1 has not been investigated.

VEGFR-1 binds VEGF-A, VEGF-B and placental growth factor (PIGF) [ 21]. VEGFR-1 gene encodes two mRNA splice variants. The full-length VEGFR-1 variant encodes a membrane bound receptor with classic intracellular tyrosine kinase signaling that positively regulates angiogenesis. The alternatively spliced variant encodes the VEGFR-1 extracellular domain resulting in a secreted protein known as soluble VEGFR-1 (sFlt-1) that is anti-angiogenic [ 22,23]. sFlt-1 sequesters the VEGFR-2 ligand, VEGF-A as well as, the VEGFR-1 specific ligands, VEGF-B and PIGF. Thus, sFlt-1 functions as a negative regulator of both VEGFR-2 and fulllength VEGFR-1 signaling and is necessary for proper embryonic angiogenesis [ 23, 24]. VEGFR-1 null ( Flt-1 -1 ) mutant embryos die because of an overgrowth of vascular endothelial cells [24]. Mice with deletion of the VEGFR-1 Tyrosine Kinase (TK) domain ( Flt-1 TK $K^{-/}$) are viable and have normal blood vessel development, but have altered macrophage migration [ 25]. In pathologic conditions, such as cancer and inflammatory diseases, full length VEGFR-1 signaling promotes angiogenesis and activates/mediates migration of macrophage-lineage cells [26]. Thus, the context and abundance of sFlt-1 and full-length VEGFR-1 determine the pro- or anti-angiogenic effect of VEGFR-1.

In this study, we determined the expression pattern of VEGFR-1 with respect to endothelial cells and macrophages in the pre- and post-implantation uterus. VEGFR-1 neutralizing antibodies were administered prior to and during implantation. Our goal was to determine if inhibition of VEGFR-1 affects decidual angiogenesis, macrophage recruitment, and/or the establishment and maintenance of pregnancy in mice. Using two different VEGFR-1 blocking antibodies, MF-1 and R\&D Systems AF471 that prevent ligand binding to VEGFR-1, we found that both vascular density and macrophage recruitment to the pregnant uterus were significantly reduced. Despite this, embryos implanted in the uterus and pregnancy progressed after VEGFR-1 blockade. We conclude that VEGFR-1 activity is required for proper decidual angiogenesis and macrophage recruitment to the implantation site during pregnancy.

\section{Materials and methods}




\section{Animal model}

The Columbia University Institutional Animal Care and Use Committee approved animal studies. Adult wildtype CD1 female mice and CD1 male mice of proven fertility were used. When mice were bred, noon on the day a mating plug was observed was designated embryonic day (E) 0.5. Uteri of non-pregnant female mice and pregnant females at E3.5 and E6.5 were embedded in Tissue-Tek ${ }^{\circledR}$ O.C.T. ${ }^{\text {TM }}$ Compound (Sakura Fine Technical Co, Ltd, Tokyo, Japan), snap-frozen on dry ice in ethanol and stored at $-80^{\circ} \mathrm{C}$.

To determine the effect of continuous VEGFR-1 blockade, females were intraperitoneally (i.p.) injected with VEGFR-1 blocking monoclonal antibody (MF-1, $132 \mathrm{mg} / \mathrm{kg}$ animal, ImClone Systems, Inc.; $\mathrm{n}=5 \mathrm{mice}$ ), antimouse VEGFR-1 antibody (AF471, $2 \mathrm{mg} / \mathrm{kg}$ animal, R\&D systems; $\mathrm{n}=1$ mice), or saline $(\mathrm{n}=5 \mathrm{mice})$ every 3 days for 18 days. MF-1 has an elimination half-life of 3 days and reaches maximal plasma concentrations 6 hours after dosing [ 27]. After 6 doses, females were mated and a final dose of antibody or saline was given on E3.5. Pregnant females were sacrificed on E7.5. Implantation sites were counted, uterine weight measured, and uteri freshly frozen in O.C.T. ${ }^{\mathrm{TM}}$ compound for sectioning. Pregnant females were sacrificed on E10.5 to determine the number of implantation sites and uterine weight.

\section{Histological staining}

For uterine analyses, $5 \mu \mathrm{m}$ transverse sections through the non-pregnant and E3.5 uteri were generated. For implantation site analyses, frontal sections through uterus/implantation site were generated for E6.5 at $7 \mu \mathrm{m}$ and for E7.5 with VEGFR-1 blockade at $12 \mu \mathrm{m}$. Implantation was confirmed by H\&E staining every 5th section. Specific staining was performed at least 3 times and 5 different uterine sections or implantation sites were analyzed.

Sections were stained as previously described [ 27]. Primary antibodies included anti-mouse VEGFR-1 (R\&D Systems, AF471), anti-mouse F4/80 (eBioscience, 14-4801), anti-mouse CD31 (BD Biosciences, 553370), antimouse endomucin (Santa Cruz, sc-65495), anti-mouse VE-cadherin (BD Biosciences, 550548), and anti-mouse CD11b (Abcam ab8878). For IHC staining, biotin rabbit anti-goat IgG (Vector, BA-5000), biotin goat anti-rat IgG (BD Biosciences, 559286), the avidin/biotin blocking kit (Vector, SP-2001), the Vectastain ABC kit and DAB substrate kit (Vector, SK-4100) were used. Sections were counterstained with hematoxylin. For IF experiments, the following secondary antibodies were used: donkey anti goat-IgG Alexa-Fluor 594 (Invitrogen, A11058) and donkey anti rat-IgG Alexa-Fluor 488 (Invitrogen, A2108). Slides were covered with Vectashield containing with 4', 6-diamidino-2-phenylindole (Vector, H-1200) for nuclear visualization.

\section{Imaging}

IHC and H\&E staining images were captured with a Nikon Eclipse E800 microscope and Nikon DXM 1200 digital camera and NIS-Elements D3.10 software or ImagePro Plus v.4.01 software. Fluorescent images were captured using a Nikon A1 scanning confocal microscope on an Eclipse Ti microscope stand (Nikon Instruments, Melville, NY). Standard lasers and filters were used to image DAPI, AlexaFluor 488, and TRITC. Images were taken using the $10 \times / 0.4$ and $60 \times / 1.49$ objectives. Representative $Z$-stacked maximum intensity images are shown.

\section{Quantitation of decidual macrophage and vascular density}

The percentage of decidua occupied by blood vessels or macrophages was calculated from E7.5 decidua frontal uterine sections by dividing the total area of CD31 or F4/80 staining by the area of the decidua multiplied by 100. Images were captured using a Nikon Eclipse E800 microscope and Nikon DXM 1200 digital camera, and data were processed using ImagePro Plus Version 4.01 (Media Cybernetics) [ 28].

\section{Serum progesterone levels}

Blood was obtained from all animals by cardiopuncture. Serum progesterone levels were measured using a competitive chemiluminescent immunoassay (Diagnostic Products Corp./Siemens) [ 9].

\section{Statistical analysis}

Data are presented as mean \pm standard error of the mean (sem). Unpaired Student t-test was used to compare sample means. $P<0.05$ was considered a statistically significant difference. Statistical analyses were performed using the Statistical Package for Social Science version 15.0 (SPSS, Inc., Chicago, Il).

\section{Results}


We determined the expression of VEGFR-1 in uterine endothelial cells (ECs) and macrophages in the postimplantation murine decidua at E6.5 (Figure 1). To determine EC expression, VEGFR-1 was co-stained with three endothelial cell markers, CD31 [ 9, 28, 29], endomucin [ 30] and VE-cadherin [ 31, 32]. To determine macrophage VEGFR-1 expression, uterine sections were stained for VEGFR-1 and either the monocyte marker, CD11b [ 33, 34] or the macrophage marker, F4/80 [ 35- 37].

Figure 1
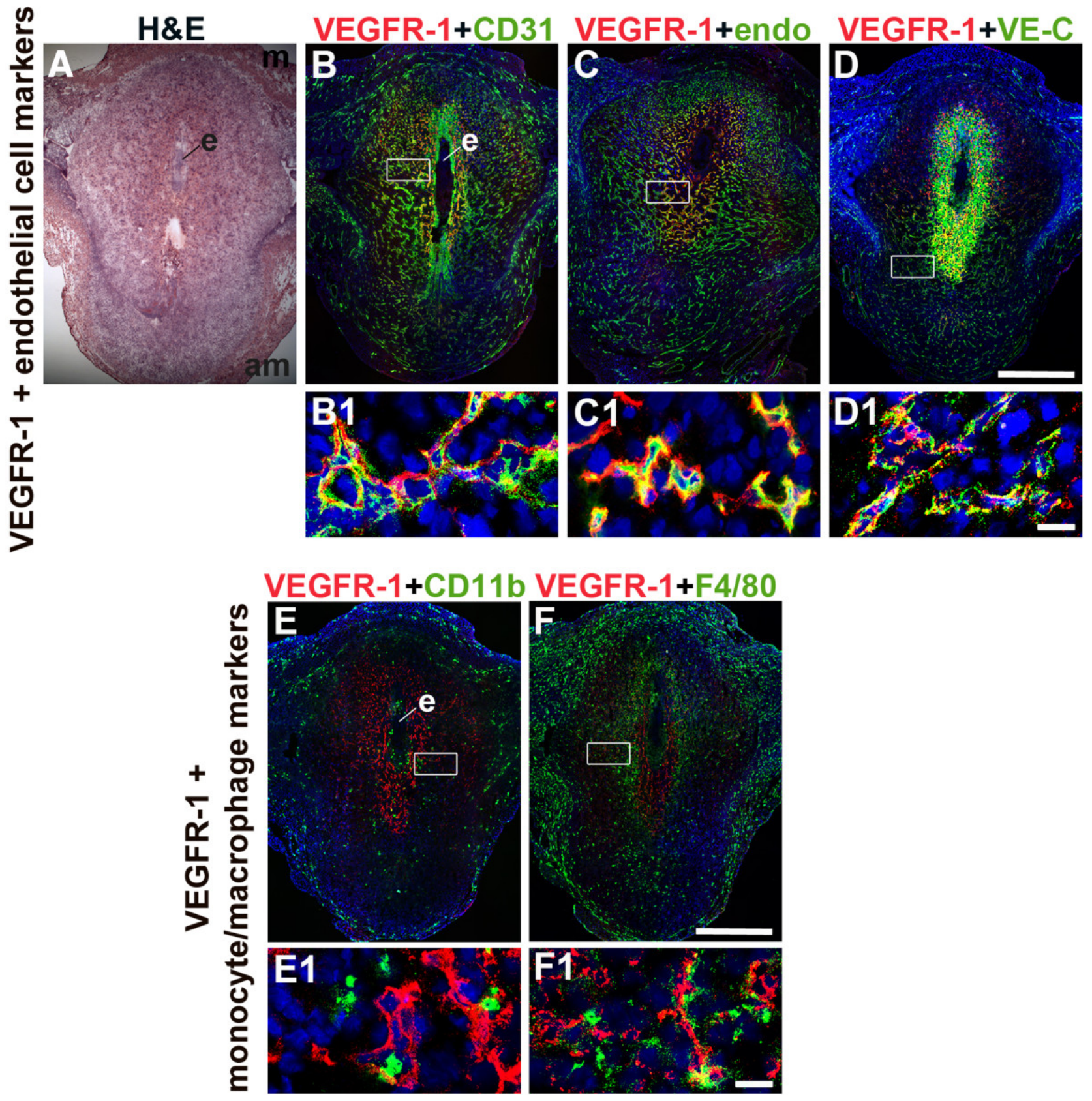

VEGFR-1 expression in endothelial cells and macrophages in the post-implantation uterus.H\&E and double staining IF were performed on E6.5 frontal uterine sections. (A)H\&E of a post-implantation mouse uterus showing the embryo (e), anti-mesometrial (am) and mesometrial (m) areas. (B-F)VEGFR-1 $1^{+}$cells (red) are observed in the decidua, with abundant expression in the primary decidual zone surrounding the implanted embryo. (B)Double-staining for VEGFR-1 $1^{+}$(red) and CD $31^{+}$(green) cells demonstrates expression of VEGFR-1 in a subset of CD31 ${ }^{+}$ECs. (C)Double-staining for VEGFR-1 ${ }^{+}$(red) and endomucin ${ }^{+}$(green) cells demonstrates expression of VEGFR-1 in a subset of endomucin ${ }^{+}$ECs. (D)Double-staining for VEGFR-1 ${ }^{+}$ (red) and VE-cadheri $\mathrm{n}^{+}$(green) cells demonstrates expression of VEGFR-1 in VE-cadherin ${ }^{+}$ECs.

(E)Double-staining for VEGFR- $1^{+}$(red) and $\mathrm{CD}_{11} \mathrm{~b}^{+}$(green) cells demonstrates that VEGFR-1 is not expressed in CD11 $\mathrm{b}^{+}$monocytes. (F)Double-staining for VEGFR-1 ${ }^{+}$(red) and F4/80 ${ }^{+}$(green) cells demonstrates that VEGFR-1 is not expressed in $\mathrm{F} 4 / 80^{+}$macrophages. VEGFR- $1^{+}$cells are adjacent to $\mathrm{CD} 11 \mathrm{~b}^{+}$monocytes and $\mathrm{F} 4 / 80^{+}$macrophages. White boxes in (B-F)indicate areas of the uteri magnified below (B1-F1). (A-F)Scale bar $=500 \mu \mathrm{m}$. (B1-F1)Scale bar $=20 \mu \mathrm{m}$. 
At E6.5, the embryo is readily detected in the post-implantation uterus (Figure $1 \mathrm{~A}$ ). VEGFR-1 ${ }^{+}$cells are most abundant in the decidua directly surrounding the implanted embryo or the primary decidual zone (Figure 1BF). $\mathrm{CD} 1^{+}$and endomucin ${ }^{+} \mathrm{ECs}$ are observed throughout the decidua (Figure $1 \mathrm{~B}, \mathrm{C}$ ), while VE-cadherin ${ }^{+} \mathrm{ECs}$ are most abundant in the anti-mesometrial decidua (Figure 1D). The positive VE-cadherin staining directly adjacent to the implanted embryo does not have a vascular pattern and does not represent ECs (Figure 1D). VEGFR-1 is expressed in decidual ECs that express CD31 (Figure 1B), endomucin (Figure 1C) or VEcadherin (Figure 1D). $\mathrm{CD}_{11 \mathrm{~b}^{+}}$monocytes and $\mathrm{F} 4 / 80^{+}$macrophages are scattered throughout the decidua, but their distribution patterns differ (Figure 1 E, F). VEGFR-1 expression is not detected in $\mathrm{CD}_{11} \mathrm{~b}^{+}$or F4/80 ${ }^{+}$decidual monocytes/macrophages (Figure 1E, F), in contrast to VEGFR-1 expression in decidual ECs. VEGFR-1 is expressed in cells that are directly adjacent to decidual monocytes/macrophages. Since VEGFR-1 expression closely overlaps with CD31 expression, CD31 was used as the EC marker for all additional experiments.

\section{VEGFR-1 is expressed in endothelial cells of the non-pregnant uterus}

In the non-pregnant uterus, $\mathrm{CD} 31^{+} \mathrm{ECs}$ and $\mathrm{F} 4 / 80^{+}$macrophages are distributed throughout the surrounding stroma and myometrium, but excluded from the uterine lumen and tubular endometrial glands that are lined by a single layer of columnar epithelium (Figure 2 A-C). VEGFR-1 expression is restricted to a subset of stromal ECs (Figure 2D). VEGFR-1 is not expressed by $\mathrm{F} 4 / 80^{+}$macrophages, but is expressed on cells adjacent to stromal macrophages (Figure 2E, F).

\section{Figure 2}


Non-pregnant

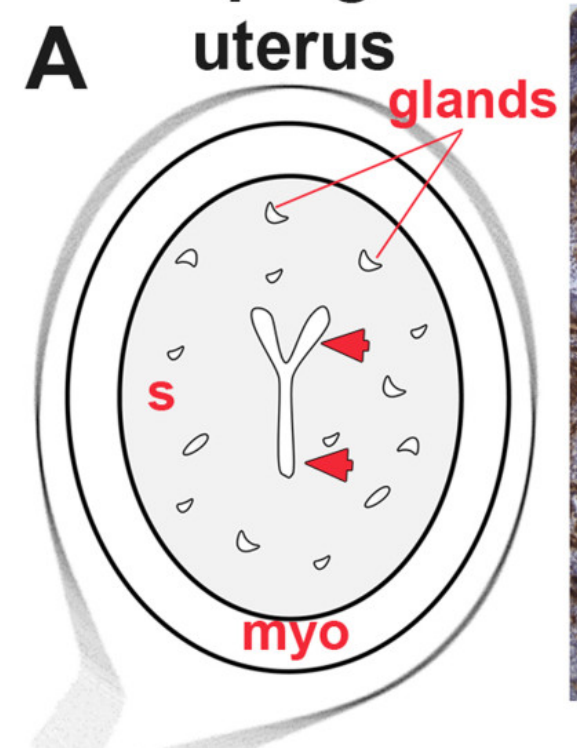

CD31

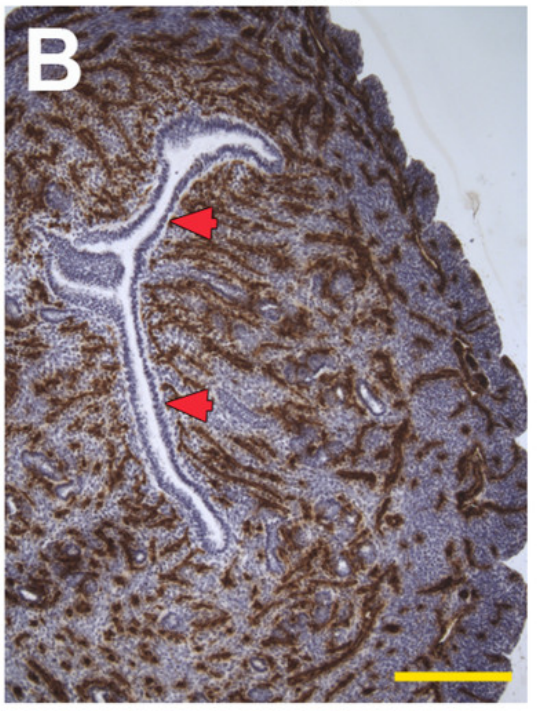

$\mathrm{F} 4 / 80$

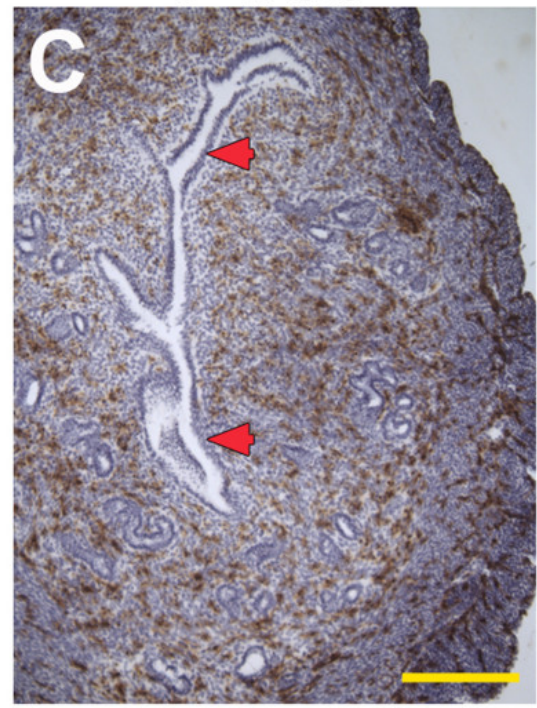

\section{VEGFR-1+CD31}
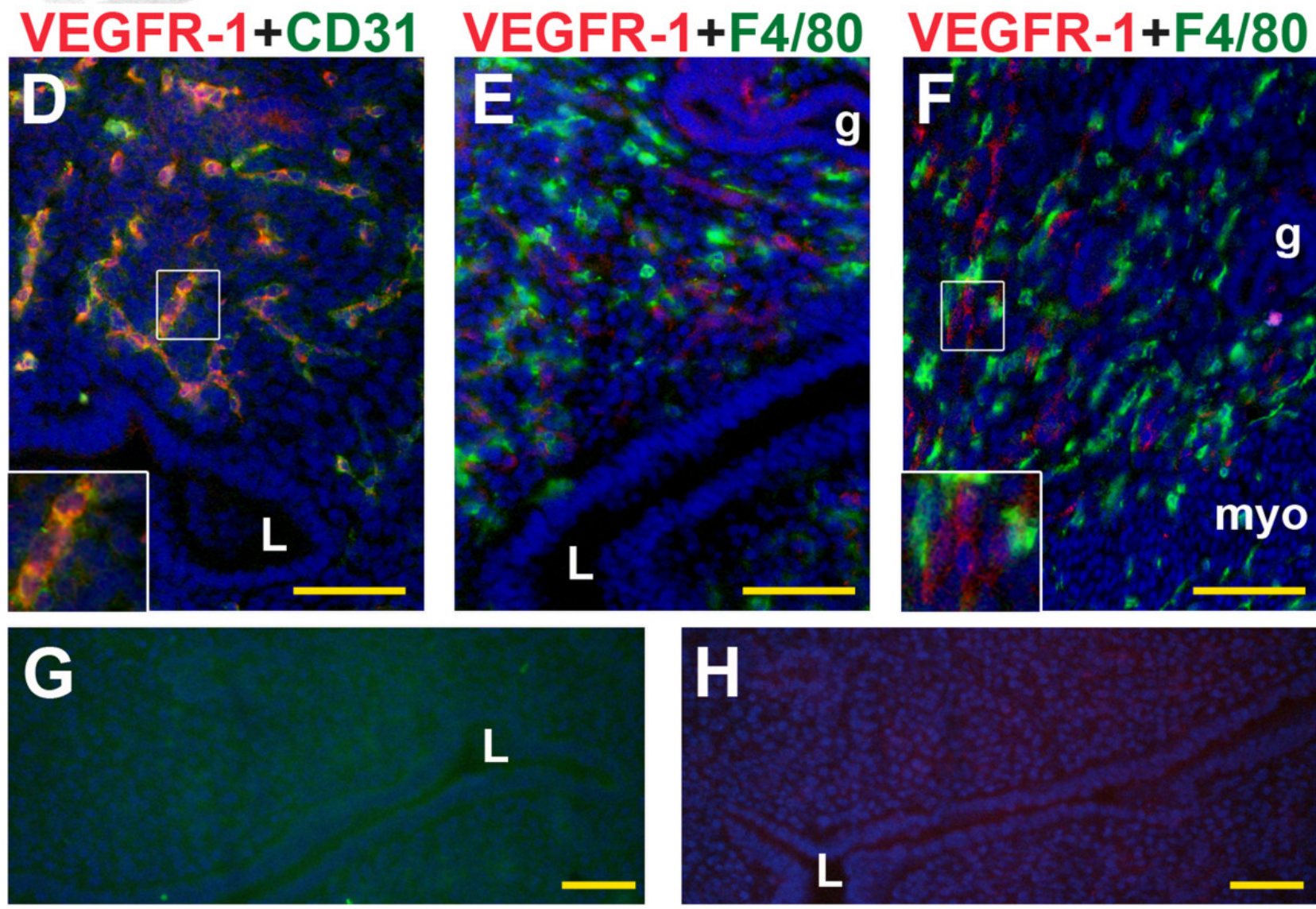

VEGFR-1, CD31 and F4/80 expression in the non-pregnant uterus.IHC and double staining IF were performed on non-pregnant uterine cross-sections. (A)Schematic representation of a non-pregnant mouse uterus showing lumen (arrowheads), endometrial glands, stroma (s), and myometrium (myo). (B)ECs, detected by CD31 staining (brown), are observed throughout the stroma and myometrium. (C)Macrophages, detected by F4/80 staining (brown), are observed throughout the stroma and myometrium. (D)Doublestaining for VEGFR-1 $1^{+}$(red) and CD31 ${ }^{+}$(green) demonstrates expression of VEGFR-1 in a subset of CD31 ${ }^{+}$ECs throughout the stroma. (E, F)VEGFR-1 ${ }^{+}$cells (red) and F4/80 ${ }^{+}$macrophages (green) are distributed throughout the stroma. VEGFR-1 and F4/80 co-expression is not observed. The inset (F)highlights contact of adjacent VEGFR-1 $1^{+}$cells and F4/80 $0^{+}$macrophages. $(\mathrm{G}, \mathrm{H}) \mathrm{IF}$ controls with secondary antibodies alone show no specific staining. L, lumen; g, endometrial gland. (B, C)Scale bar $=100 \mu \mathrm{m}$. (D-H)Scale bar $=$ $50 \mu \mathrm{m}$.

\section{VEGFR-1 is expressed in endothelial cells of the pre-implantation uterus}

By E3.5, progesterone secretion by ovarian corpora lutea has been initiated to prepare the endometrium for embryo implantation. The gross appearance of the E3.5 pre-implantation uterus is similar to the non-pregnant 
uterus (Figures $2 \mathrm{~A}$ and $3 \mathrm{~A}$ ). As in the non-pregnant state, CD31+ $\mathrm{ECs}$ (Figure $3 \mathrm{~B}$ ) and F4/80 macrophages (Figure 3C) are distributed throughout the stroma and myometrium. Similar to the non-pregnant state, CD31 ${ }^{+}$ECs and F4/80 ${ }^{+}$macrophages (Figure 3C, F) are abundant adjacent to the lumen and glands at E3.5. VEGFR$1^{+}$cells are observed throughout the stroma (Figure 3D). VEGFR-1 expression was cell associated consistent with the antibody detecting full-length VEGFR-1 on the cell surface (Figure 3E, inset). Co-staining with CD31 reveals that most VEGFR-1 ${ }^{+}$cells are ECs (Figure $3 \mathrm{E}$ ). As in the non-pregnant state, VEGFR-1 ${ }^{+}$cells are found adjacent to $\mathrm{F} 4 / 80^{+}$macrophages (Figure $3 \mathrm{~F}$ ) and $\mathrm{CD} 11 \mathrm{~b}^{+}$monocytes (Figure $3 \mathrm{G}$ ).

\title{
Figure 3
}

\section{E3.5 uterus}

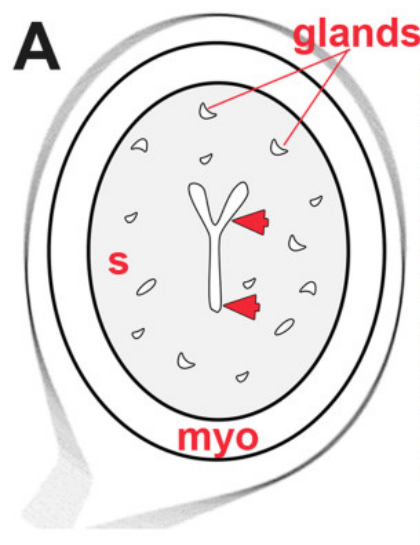

CD31
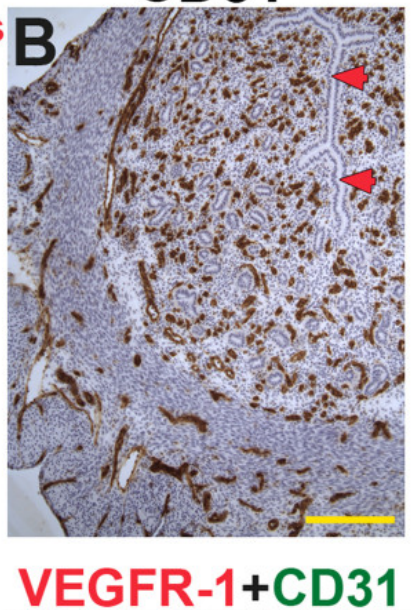
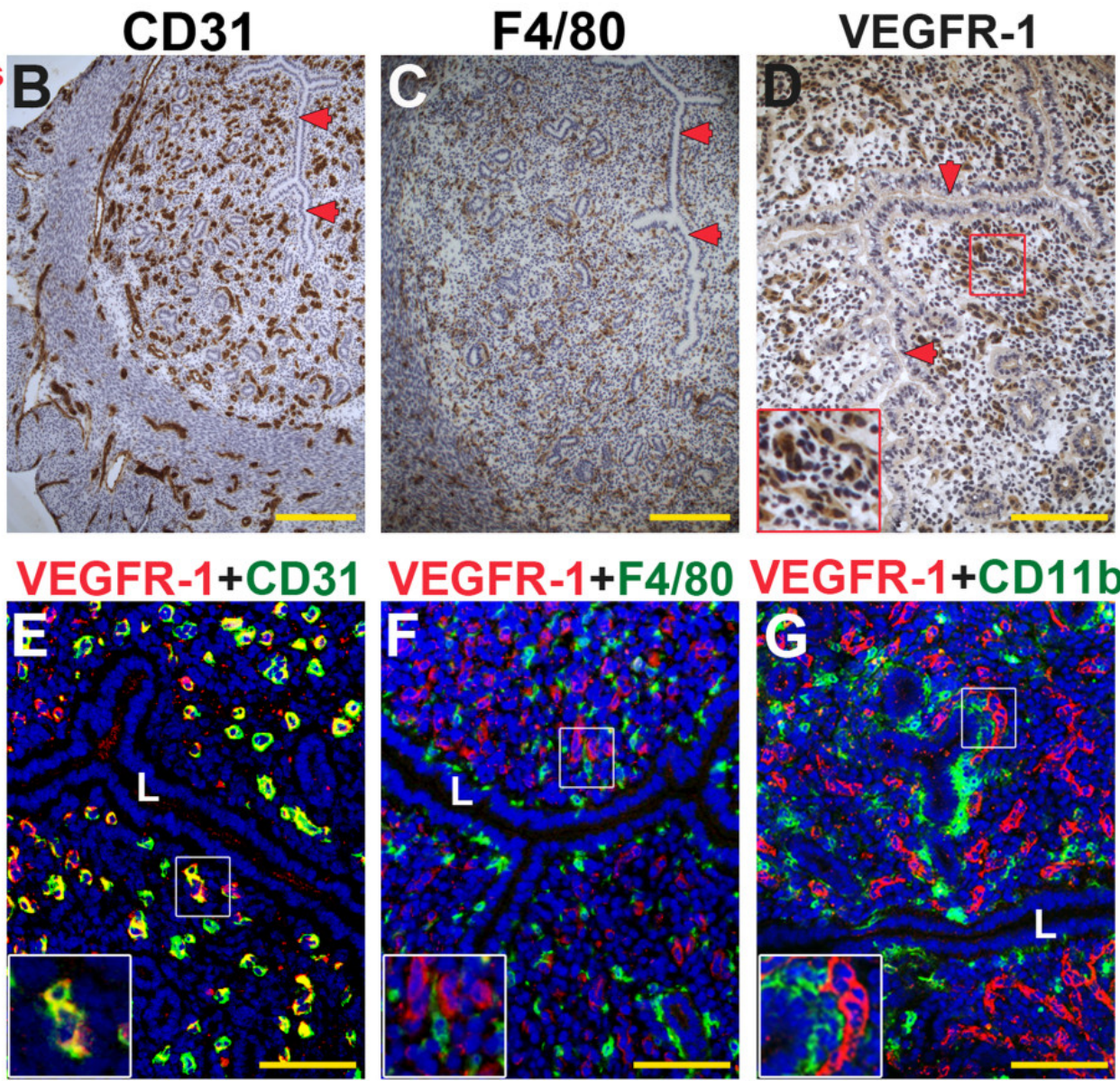

\begin{abstract}
VEGFR-1, CD31, F4/80, and CD11b expression in the pre-implantation mouse uterus.IHC and double staining IF were performed on E3.5 uterine cross-sections. (A)Schematic representation of an E3.5 mouse uterus showing lumen (arrowheads), glands, stroma (s), and myometrium (myo). (B)ECs, detected by CD31 staining (brown), are observed throughout the stroma and myometrium, similar to the non-pregnant state. (C)Macrophages, detected by F4/80 staining (brown), are observed throughout the stroma and are abundant adjacent to the lumen and glands at E3.5. (D)VEGFR $-1^{+}$cells (brown), are distributed throughout the stroma and cell associated VEGFR-1 expression highlighted in the inset. (E)Double staining for VEGFR-1 (red) and CD31 (green) demonstrates expression of VEGFR-1 on CD31 $1^{+}$ECs throughout the stroma. (F)VEGFR-1 ${ }^{+}$cells (red) and F4/80 ${ }^{+}$macrophages (green) are distributed throughout the stroma. VEGFR-1 and F4/80 coexpression is not observed. (G)VEGFR-1 $1^{+}$cells (red) and CD11 $\mathrm{b}^{+}$monocytes (green) are distributed throughout the stroma. VEGFR-1 and CD11b co-expression is not observed. L, lumen. Scale bars B, C = $100 \mu \mathrm{m}$. Scale bars D $-\mathrm{F}=50 \mu \mathrm{m}$.
\end{abstract}

\section{VEGFR-1 is expressed in endothelial cells of the post-implantation uterus}

With embryo-uterine contact during implantation, stromal cells are transformed into large, polygonal, glycogen and lipid rich decidual cells. By E6.5, the primary and secondary decidual zones are defined by morphologic differences in decidual cells, as well as differential expression of tight junction proteins and VEGF receptors [ 9, 29, 38, 39] (Figure 4A). CD 31 $1^{+}$ECs are abundant throughout the decidua, the endometrium surrounding the implanted embryo, and myometrium (Figure $4 \mathrm{~B}, \mathrm{~F}$, and G). F4/80 $0^{+}$macrophages are scattered throughout the decidua and most abundant in the myometrium and stroma directly adjacent to the myometrium (Figure 4C, I, $\mathrm{J}$ ). Within the decidua, the secondary decidual zone (SDZ) contains the highest concentration of F4/80 ${ }^{+}$macrophages (Figure 4C). VEGFR-1 $1^{+}$cells are most abundant in the primary decidual zone (PDZ) (Figure 4D, E, H). Most VEGFR- $1^{+}$cells are ECs (Figure 4E) and within the PDZ, VEGFR-1 ${ }^{+}$cells are found adjacent 
to $\mathrm{F} 4 / 80^{+}$macrophages (Figure $4 \mathrm{H}$ ). As in the pre-implantation uterus, VEGFR-1 expression in decidual ECs is consistent with full-length VEGFR-1 (Figure $4 \mathrm{E}, \mathrm{H}$, insets). The distribution pattern of VEGFR- $1^{+} \mathrm{ECs}$ and macrophages suggests that VEGFR-1 $1^{+} \mathrm{EC}$ and $\mathrm{F} 4 / 80^{+}$macrophages are in direct contact in both the nonpregnant, peri-implantation and post-implantation uterus.

\section{Figure 4}
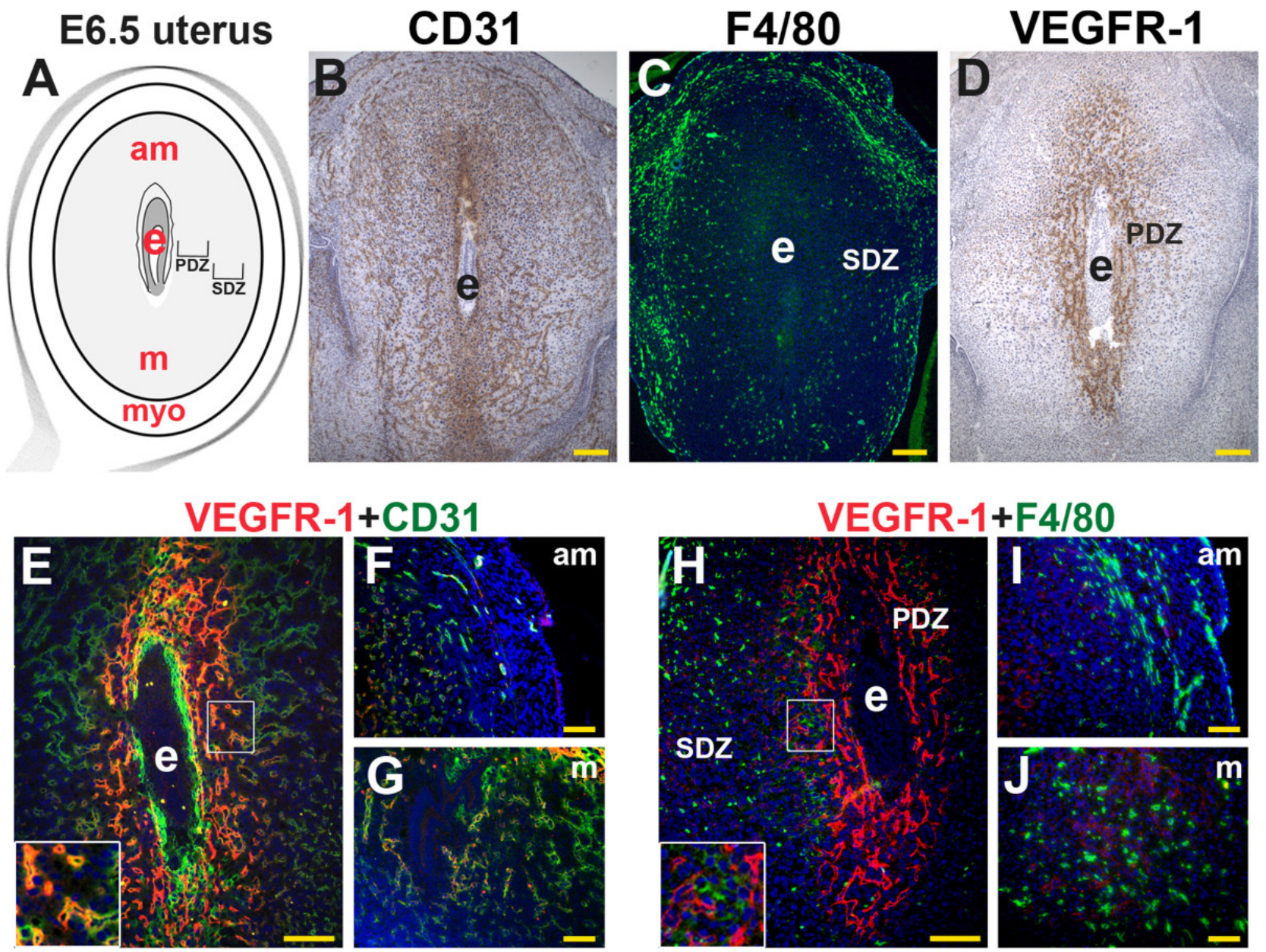

VEGFR-1, CD31, and F4/80 in the post-implantation mouse uterus.IHC and double staining IF were performed on E6.5 frontal uterine sections. (A)Schematic representation of an E6.5 mouse uterus showing the embryo (e), anti-mesometrial (am) and mesometrial (m) areas, and myometrium (myo). (B)CD31 ${ }^{+}$ECs (brown) are abundant in the decidua around the implanted embryo and the myometrium. (C)A majority of $\mathrm{F} 4 / 80^{+}$macrophages (green) are observed in the secondary decidual zone (SDZ) and myometrium. (D)A majority of VEGFR $-1^{+}$cells (brown) are observed in the primary decidual zone (PDZ) directly adjacent to the implanted embryo. (E-F)Double staining of VEGFR-1 (red) and CD31 ${ }^{+}$(green) demonstrates (E)coexpression in the ECs within the PDZ (inset), (F, G)and minimal co-expression of VEGFR-1 and CD31 in the abundant ECs in the SDZ of the anti-mesometrial and mesometrial poles. (H)Double staining for

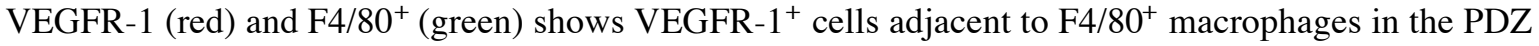
(inset). (I, J)F4/80 $0^{+}$macrophages are abundant in the $\mathrm{SDZ}$ of the anti-mesometrial pole and mesometrial poles, where VEGFR-1 expression is low to absent. (B-D, H)Scale bars $=100 \mu \mathrm{m}$. (F, G, I, J)Scale bars $=$ $50 \mu \mathrm{m}$.

\section{Effects of VEGFR-1 blockade on pregnancy, decidual macrophages and vascular density}

Previous studies demonstrated that a single dose of VEGFR-1 blocking antibody MF-1, administered on E3.75, had no effect on decidual angiogenesis or pregnancy [9]. In this study, we administered 6 doses of MF-1 prior to mating and a single dose on E3.5, one day prior to implantation, to determine the effect of continuous VEGFR-1 blockade on pregnancy. Administration of VEGFR-1 blocking antibody MF-1 had no effect on the number of implantation sites or uterine weights at E7.5 and E10.5 (Table 1). Histological analysis of uterine tissues sections confirmed normal embryonic development at E7.5 and E10.5 (data not shown). However, differences in macrophage and vascular density were observed. At E7.5, F4/80 $0^{+}$macrophage and CD31 ${ }^{+} \mathrm{EC}$ densities were both significantly decreased in MF-1 treated uteri compared to controls (Figure 5 and Table 1). 
VEGFR-1 blockade with R\&D Systems AF471 antibody also resulted in decreased macrophage numbers and vascular density at E7.5 (Figure 5B).

Table 1

\begin{tabular}{l|c|c|c|c}
\hline & \multicolumn{2}{|c|}{ Anti-VEGFR-1 (MF-1) } & \multicolumn{2}{c}{ Control } \\
& E7.5 & E10.5 & E7.5 & E10.5 \\
\hline Implantation sites $(\#)$ & $13 \pm 0.6$ & $12.1 \pm 0.4$ & $13 \pm 0.3$ & $11.8 \pm 0.9$ \\
Uterine weights $(\mathrm{g})$ & $0.35 \pm 0.01$ & $2.1 \pm 0.1$ & $0.36 \pm 0.02$ & $2.3 \pm 0.1$ \\
Serum progesterone $(\mathrm{ng} / \mathrm{mL})$ & $23.4 \pm 2.3$ & & $27.9 \pm 1.1$ & \\
Macrophage density & $6.7 \times 10^{-5} \pm 1.1 \times 10^{-6 \mathrm{a}}$ & & $2.5 \times 10^{-5} \pm 4.3 \times 10^{-7 \mathrm{a}}$ & \\
Vascular density & $13.1 \pm 0.2^{\mathrm{b}}$ & & $6.3 \pm 0.2^{\mathrm{b}}$ & \\
\hline
\end{tabular}

a, b $P<0.01$.

Effect of anti-VEGFR-1 blocking antibody MF-1 on pregnancy, decidual macrophages and vascular density

Figure 5 

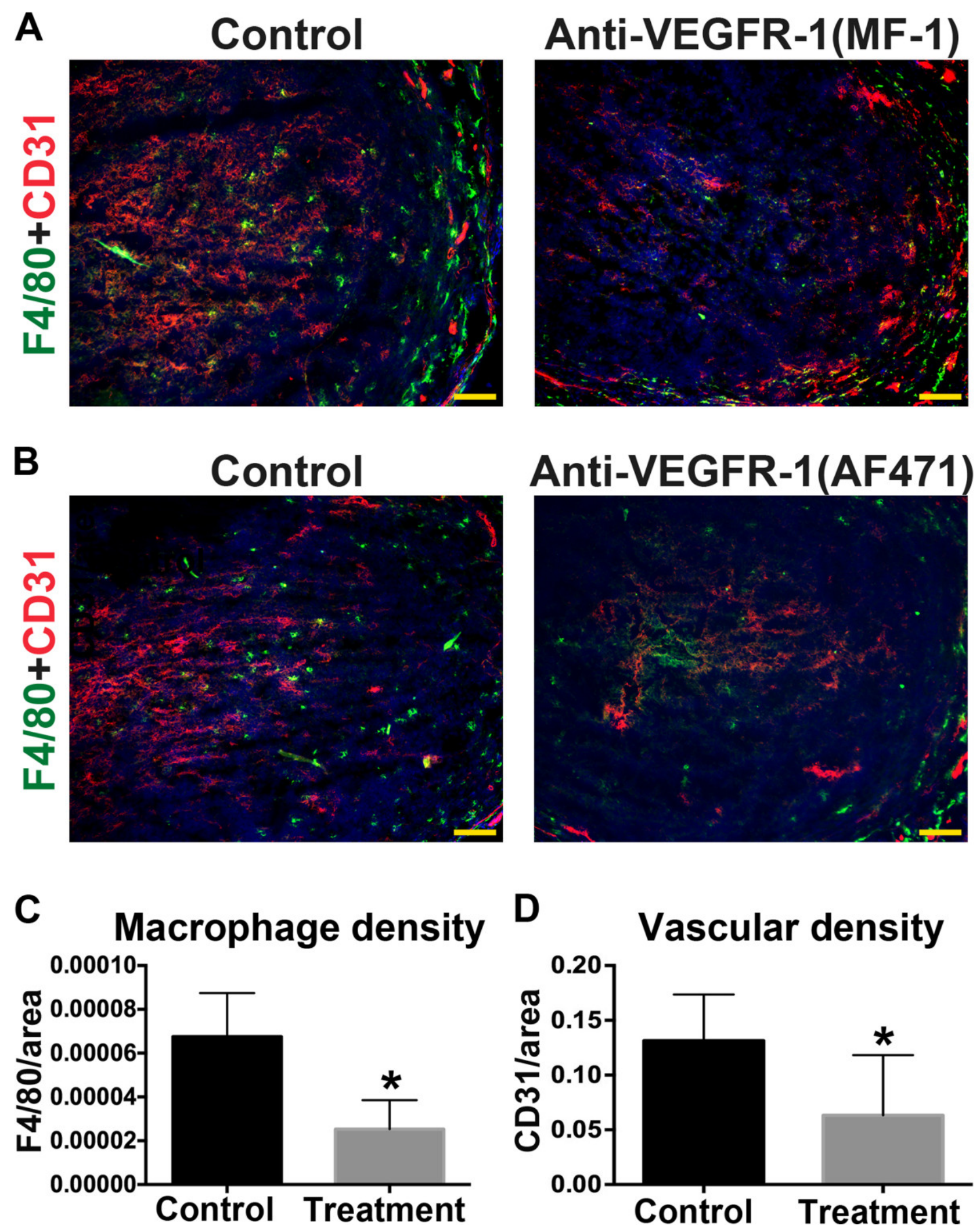

\footnotetext{
VEGFR-1 blockade reduces peri-implantation macrophage and vascular density at E7.5. (A, B)Double staining for F4/80 (green) and CD31 (red) in E7.5 uterine frontal sections from mice treated with VEGFR-1 blocking antibodies (MF-1 or AF471) or from control mice. Reduced expression of F4/80 and CD31 is observed in treatment groups. Scale bars $=50 \mu \mathrm{m} .(\mathrm{C}, \mathrm{D}) \mathrm{F} 4 / 80^{+}$or $\mathrm{CD} 31^{+}$signal was determined and normali zed by total decidual area. $\mathrm{F} 4 / 80^{+}$macrophage and $\mathrm{CD} 31^{+} \mathrm{EC}$ density is significantly reduced in uteri of mice that received MF-1 compared to controls.
}

To confirm that blocking VEGFR-1 did not affect ovarian function, we measured serum progesterone levels at E7.5. The mean serum progesterone level was similar in MF-1 treated mice and controls $(23.4 \pm 2.3 \mathrm{vs} .27 .9 \pm$ $1.1 \mathrm{ng} / \mathrm{mL}$, Table 1), indicating that VEGFR-1 blockage did not affect corpora lutea function in this model. Thus, the observed uterine defects can be attributed to the direct affects of VEGFR-1 blockade on the uterus. 
We have previously shown that peri-implantation inhibition of VEGFR-2 significantly reduces vascular density and causes pregnancy loss by E10.5. We showed that only a subset of endothelial cells express VEGFR-1 and peri-implantation inhibition with a single dose of VEGFR-1 blocking antibody at E3.75 does not affect vascular density or pregnancy [ 9]. Our present evaluation of VEGFR-1 expression with respect to endothelial cells and macrophages shows that VEGFR-1 expression is mainly restricted to uterine and decidual endothelial cells, while VEGFR-1 is not expressed in monocytes and macrophages. Endothelial cells expressing VEGFR-1 were often in direct contact with $\mathrm{CD} 11 \mathrm{~b}^{+}$monocytes and $\mathrm{F} 4 / 80^{+}$macrophages. Finally repeated pre-implantation injections of a VEGFR-1 blocking antibody, significantly decrease both the number of macrophages and vascular density in the decidua of E7.5 pregnant mice. Taken together, our results suggest that the decreased vascularity observed at E7.5 is a direct result of VEGFR-1 blockade, whereas the reduction in macrophages may be an indirect result of the decrease in VEGFR-1 function in the endothelial cells.

Treatment with MF-1, which blocks binding of VEGF-A and PIGF to VEGFR-1, can have pro- or antiangiogenic effects, depending on the context of VEGFR-1 function [ 26, 40- 42]. PlGF signaling, via membrane-localization of full length VEGFR-1, plays a pro-angiogenic role in pathological angiogenesis [ 26, 42]. In murine decidual angiogenesis, VEGFR-1 appears to be membrane associated consistent with full-length receptor expression (Figures 1 and $3 \mathrm{E}, \mathrm{H}$ ). Thus, the reduced angiogenesis we observed is likely due to blocking ligand-dependent VEGFR-1 pro-angiogenic signaling. However, it has been previously shown that the VEGFR-1 TK domain is not necessary for murine decidual angiogenesis [ 29]. Thus the pro-angiogenic role for VEGFR-1, we observed may be independent of VEGFR-1 TK signaling pathway.

We have shown that a single dose of MF-1 administered within 24 hours of implantation does not affect vascular density [ 9], but continuous VEGFR-1 blockade results in a 48\% reduction in vascular density (Figure 5D). A greater than 50\% reduction in decidual vascular density with VEGFR-2 blockade results in pregnancy loss, likely due to loss of angiogenesis in both the primary and secondary decidual zones [9]. In contrast, inhibition of VEGFR-3 results in a less than 50\% decrease in primary decidual zone angiogenesis, but does not lead to pregnancy loss [ 9]. Combined, these data suggest that implantation and early pregnancy can tolerate a less than $50 \%$ reduction of vascular density in the primary decidual zone.

Macrophages are prominent in the adult ovary and uterus, two organs with physiological cyclical angiogenesis regulated by the VEGF/VEGFR-2 signaling pathway [ 9, 28, 43]. The number and phenotype of macrophages in the non-pregnant uterus changes with the ovarian cycle and additional macrophages are recruited into the endometrium during the peri-implantation period [ 20,44]. It has been shown that pre-implantation macrophage ablation prevents embryo implantation and results in infertility [20]. However, fertility is restored when macrophage-depleted mice are supplemented with exogenous progesterone suggesting a defect in corpora lutea function. In fact, macrophages have been shown to regulate corpus lutea development and function, specifically the synthesis of progesterone that is required for embryo implantation and establishing pregnancy [ 20,45]. Thus, uterine macrophages may not be necessary for embryo implantation. We found that pregnancy can tolerate a reduction of macrophages by $37 \%$ of normal. Taken together, the data suggest that macrophages do not have an obligatory role in the uterine decidualization and implantation of the embryo. However the role of macrophages after embryo implantation still remains to be elucidated.

\section{Declarations}

\section{Acknowledgement}

Images were collected in the Confocal and Specialized Microscopy Shared Resource of the Herbert Irving Comprehensive Cancer Center at Columbia University Medical Center.

\section{Authors' original submitted files for images}

Below are the links to the authors' original submitted files for images.

Authors' original file for figure 1

Authors' original file for figure 2

Authors' original file for figure 3

Authors' original file for figure 4

Authors' original file for figure 5

\section{Competing interests}

The authors declare that they have no competing interests. 


\section{Authors' contributions}

ND prepared the manuscript and all figures. RZ and QKT did the experiments with MF-1 and R\&D Systems AF471. CSP did the immunohistochemistry. JK and MS reviewed and edited the final manuscript. CS prepared and edited the manuscript. All authors read and approved the final manuscript.

\section{References}

1. Dey SK, Lim H, Das SK, Reese J, Paria BC, Daikoku T, Wang H. Molecular cues to implantation. Endocr Rev. 2004;25:341-373.

View Article Google Scholar

2. Cha J, Sun X, Dey SK. Mechanisms of implantation: strategies for successful pregnancy. Nat Med. 2012;18:1754-1767.

View Article Google Scholar

3. Wang H, Dey SK. Roadmap to embryo implantation: clues from mouse models. Nat Rev Genet. 2006;7:185-199.

View Article Google Scholar

4. Kabawat SE Mostoufi-Zadeh M Driscoll SG Bhan AK Implantation site in normal pregnancy. A study with monoclonal antibodies Am J Pathol 198511876841887848

5. Fest S, Aldo PB, Abrahams VM, Visintin I, Alvero A, Chen R, Chavez SL, Romero R, Mor G.

Trophoblast-macrophage interactions: a regulatory network for the protection of pregnancy. Am J Reprod Immunol. 2007;57:55-66.

View Article Google Scholar

6. Rabbani ML, Rogers PA. Role of vascular endothelial growth factor in endometrial vascular events before implantation in rats. Reproduction. 2001;122:85-90.

View Article Google Scholar

7. Rockwell LC, Pillai S, Olson CE, Koos RD. Inhibition of vascular endothelial growth factor/vascular permeability factor action blocks estrogen-induced uterine edema and implantation in rodents. Biol Reprod. 2002;67:1804-1810.

View Article Google Scholar

8. Sengupta J, Lalitkumar PG, Najwa AR, Charnock-Jones DS, Evans AL, Sharkey AM, Smith SK, Ghosh D. Immunoneutralization of vascular endothelial growth factor inhibits pregnancy establishment in the rhesus monkey (Macaca mulatta). Reproduction. 2007;133:1199-1211. View Article Google Scholar

9. Douglas NC Tang H Gomez R Pytowski B Hicklin DJ Sauer CM Kitajewski J Sauer MV Zimmermann RC Vascular endothelial growth factor receptor 2 (VEGFR-2) functions to promote uterine decidual angiogenesis during early pregnancy in the mouse Endocrinology 2009 150384538542717882 10.1210/en.2008-1207

10. Co EC Gormley M Kapidzic M Rosen DB Scott MA Stolp HA McMaster M Lanier LL Barcena A Fisher SJ Maternal decidual macrophages inhibit NK cell killing of invasive cytotrophoblasts during human pregnancy Biol Reprod 2013881554070869 10.1095/biolreprod.112.099465

11. Vince GS, Starkey PM, Jackson MC, Sargent IL, Redman CW. Flow cytometric characterisation of cell populations in human pregnancy decidua and isolation of decidual macrophages. J Immunol Methods. 1990;132:181-189.

View Article Google Scholar

12. Lessin DL, Hunt JS, King CR, Wood GW. Antigen expression by cells near the maternal-fetal interface. Am J Reprod Immunol Microbiol. 1988;16:1-7.

View Article Google Scholar 
13. Wang WJ, Hao CF, Lin QD. Dysregulation of macrophage activation by decidual regulatory T cells in unexplained recurrent miscarriage patients. J Reprod Immunol. 2011;92:97-102.

View Article Google Scholar

14. Guenther S Vrekoussis T Heublein S Bayer B Anz D Knabl J Navrozoglou I Dian D Friese K Makrigiannakis A Jeschke U Decidual macrophages Are significantly increased in spontaneous miscarriages and over-express FasL: a potential role for macrophages in trophoblast apoptosis Int J Mol Sci 201213906990803430283 10.3390/ijms13079069

15. Kofler NM Shawber CJ Kangsamaksin T Reed HO Galatioto J Kitajewski J Notch signaling in developmental and tumor angiogenesis Genes Cancer 20112110611163411124 $10.1177 / 1947601911423030$

16. Turner EC Hughes J Wilson H Clay M Mylonas KJ Kipari T Duncan WC Fraser HM Conditional ablation of macrophages disrupts ovarian vasculature Reproduction 2011141821 8313101494 10.1530/REP-10-0327

17. Pipp F, Heil M, Issbrucker K, Ziegelhoeffer T, Martin S, van den Heuvel J, Weich H, Fernandez B, Golomb G, Carmeliet P, Schaper W, Clauss M. VEGFR-1-selective VEGF homologue PlGF is arteriogenic: evidence for a monocyte-mediated mechanism. Circ Res. 2003;92:378-385.

View Article Google Scholar

18. Murakami M, Zheng Y, Hirashima M, Suda T, Morita Y, Ooehara J, Ema H, Fong GH, Shibuya M. VEGFR1 tyrosine kinase signaling promotes lymphangiogenesis as well as angiogenesis indirectly via macrophage recruitment. Arterioscler Thromb Vasc Biol. 2008;28:658-664.

View Article Google Scholar

19. Fantin A Vieira JM Gestri G Denti L Schwarz Q Prykhozhij S Peri F Wilson SW Ruhrberg C Tissue macrophages act as cellular chaperones for vascular anastomosis downstream of VEGFmediated endothelial tip cell induction Blood 20101168298402938310 10.1182/blood-2009$12-257832$

20. Care AS Diener KR Jasper MJ Brown HM Ingman WV Robertson SA Macrophages regulate corpus luteum development during embryo implantation in mice J Clin Invest 20131233472 34873726148 10.1172/JCI60561

21. Ferrara N, Gerber HP, LeCouter J. The biology of VEGF and its receptors. Nat Med. 2003;9:669-676. View Article Google Scholar

22. Shibuya M Vascular endothelial growth factor (VEGF) and its receptor (VEGFR) signaling in angiogenesis: a crucial target for anti- and Pro-angiogenic therapies Genes Cancer 201121097 $1105341112510.1177 / 1947601911423031$

23. Shibuya M. Vascular endothelial growth factor receptor-1 (VEGFR-1/Flt-1): a dual regulator for angiogenesis. Angiogenesis. 2006;9:225-230.

View Article Google Scholar

24. Fong GH, Rossant J, Gertsenstein M, Breitman ML. Role of the Flt-1 receptor tyrosine kinase in regulating the assembly of vascular endothelium. Nature. 1995;376:66-70.

View Article Google Scholar

25. Hiratsuka S Minowa O Kuno J Noda T Shibuya M Flt-1 lacking the tyrosine kinase domain is sufficient for normal development and angiogenesis in mice Proc Natl Acad Sci 1998959349 935421341 10.1073/pnas.95.16.9349

26. Luttun A, Tjwa M, Moons L, Wu Y, Angelillo-Scherrer A, Liao F, Nagy JA, Hooper A, Priller J, De Klerck B, Compernolle V, Daci E, Bohlen P, Dewerchin M, Herbert JM, Fava R, Matthys P, Carmeliet G, Collen D, Dvorak HF, Hicklin DJ, Carmeliet P. Revascularization of ischemic tissues by PIGF 
treatment, and inhibition of tumor angiogenesis, arthritis and atherosclerosis by anti-Flt 1 . Nat Med. 2002;8:831-840.

View Article Google Scholar

27. Wu Y, Zhong Z, Huber J, Bassi R, Finnerty B, Corcoran E, Li H, Navarro E, Balderes P, Jimenez X, Koo H, Mangalampalli VR, Ludwig DL, Tonra JR, Hicklin DJ. Anti-vascular endothelial growth factor receptor-1 antagonist antibody as a therapeutic agent for cancer. Clin Cancer Res. 2006; 12:6573-6584.

View Article Google Scholar

28. Vorontchikhina MA, Zimmermann RC, Shawber CJ, Tang H, Kitajewski J. Unique patterns of Notch1, Notch4 and Jagged1 expression in ovarian vessels during folliculogenesis and corpus luteum formation. Gene Expr Patterns. 2005;5:701-709.

View Article Google Scholar

29. Kim M Park HJ Seol JW Jang JY Cho YS Kim KR Choi Y Lydon JP Demayo FJ Shibuya M Ferrara N Sung HK Nagy A Alitalo K Koh GY VEGF-A regulated by progesterone governs uterine angiogenesis and vascular remodelling during pregnancy EMBO Mol Med 201351415 $1430379949510.1002 / \mathrm{emmm} .201302618$

30. Brachtendorf G, Kuhn A, Samulowitz U, Knorr R, Gustafsson E, Potocnik AJ, Fassler R, Vestweber D. Early expression of endomucin on endothelium of the mouse embryo and on putative hematopoietic clusters in the dorsal aorta. Dev Dyn. 2001;222:410-419.

View Article Google Scholar

31. Nakhuda GS, Zimmermann RC, Bohlen P, Liao F, Sauer MV, Kitajewski J. Inhibition of the vascular endothelial cell (VE)-specific adhesion molecule VE-cadherin blocks gonadotropin-dependent folliculogenesis and corpus luteum formation and angiogenesis. Endocrinology. 2005;146:10531059.

View Article Google Scholar

32. Groten T, Fraser HM, Duncan WC, Konrad R, Kreienberg R, Wulff C. Cell junctional proteins in the human corpus luteum: changes during the normal cycle and after HCG treatment. Hum Reprod. 2006;21:3096-3102.

View Article Google Scholar

33. Rosmarin AG, Weil SC, Rosner GL, Griffin JD, Arnaout MA, Tenen DG. Differential expression of CD11b/CD18 (Mo1) and myeloperoxidase genes during myeloid differentiation. Blood. 1989;73:131-136.

View Article Google Scholar

34. Keenihan SN, Robertson SA. Diversity in phenotype and steroid hormone dependence in dendritic cells and macrophages in the mouse uterus. Biol Reprod. 2004;70:1562-1572.

View Article Google Scholar

35. De M, Choudhuri R, Wood GW. Determination of the number and distribution of macrophages, lymphocytes, and granulocytes in the mouse uterus from mating through implantation. J Leukoc Biol. 1991;50:252-262.

View Article Google Scholar

36. De M, Wood GW. Analysis of the number and distribution of macrophages, lymphocytes, and granulocytes in the mouse uterus from implantation through parturition. J Leukoc Biol. 1991;50:381-392.

View Article Google Scholar

37. Brandon JM. Macrophage distribution in decidual tissue from early implantation to the periparturient period in mice as defined by the macrophage differentiation antigens F4/80, macrosialin and the type 3 complement receptor. J Reprod Fertil. 1995;103:9-16. 
38. Paria BC, Zhao X, Das SK, Dey SK, Yoshinaga K. Zonula occludens-1 and E-cadherin are coordinately expressed in the mouse uterus with the initiation of implantation and decidualization. Dev Biol. 1999;208:488-501.

View Article Google Scholar

39. Chakraborty I, Das SK, Dey SK. Differential expression of vascular endothelial growth factor and its receptor mRNAs in the mouse uterus around the time of implantation. J Endocrinol. 1995; 147:339-352.

View Article Google Scholar

40. Wang ES, Teruya-Feldstein J, Wu Y, Zhu Z, Hicklin DJ, Moore MA. Targeting autocrine and paracrine VEGF receptor pathways inhibits human lymphoma xenografts in vivo. Blood. 2004;104:28932902.

View Article Google Scholar

41. Huang H Shen J Vinores SA Blockade of VEGFR1 and 2 suppresses pathological angiogenesis and vascular leakage in the eye PLoS One 20116 e214113120882

10.1371/journal.pone.0021411

42. Carmeliet P, Moons L, Luttun A, Vincenti V, Compernolle V, De Mol M, Wu Y, Bono F, Devy L, Beck H, Scholz D, Acker T, DiPalma T, Dewerchin M, Noel A, Stalmans I, Barra A, Blacher S,

VandenDriessche T, Ponten A, Eriksson U, Plate KH, Foidart JM, Schaper W, Charnock-Jones DS, Hicklin DJ, Herbert JM, Collen D, Persico MG. Synergism between vascular endothelial growth factor and placental growth factor contributes to angiogenesis and plasma extravasation in pathological conditions. Nat Med. 2001;7:575-583.

View Article Google Scholar

43. Fraser HM, Duncan WC. SRB reproduction, fertility and development award lecture 2008.

Regulation and manipulation of angiogenesis in the ovary and endometrium. Reprod Fertil Dev. 2009;21:377-392.

View Article Google Scholar

44. De M, Wood GW. Influence of oestrogen and progesterone on macrophage distribution in the mouse uterus. J Endocrinol. 1990;126:417-424.

View Article Google Scholar

45. Kirsch TM, Friedman AC, Vogel RL, Flickinger GL. Macrophages in corpora lutea of mice: characterization and effects on steroid secretion. Biol Reprod. 1981;25:629-638.

View Article Google Scholar 